International Journal on Cybernetics \& Informatics (IJCI) Vol. 3, No. 3, June 2014

\title{
INTELLIGENT ANALYSIS OF THE EFFECT OF INTERNET SYSTEM IN SOCIETY
}

\author{
Rashmi Chahar $^{1}$, Ashish Chandiok ${ }^{2}$ and D. K. Chaturvedi ${ }^{3}$ \\ ${ }^{1,2,3}$ Dayalbagh Educational Institute, Dayalbagh, Agra, Uttar Pradesh, India
}

\begin{abstract}
This paper analyzes the effect of Information Technology on professionals, academicians and students in perspective of their relations, education, job purpose, health, entertainment and electronic business that can bring changes in society. Technology can have both positive and negative consequences for people of different walks of life at different times. The need is to understand the true impact of internet on the society so that people can start thinking and build a healthy society. In this paper, an empirical study is considered 60 persons; a causal loop model is formed relating the parameters on the basis of data collected. These parameters are used to form the fuzzy dynamic model to analyze the effect of the internet on the society. The model is analyzed and suitable solutions are proposed to counter the negative effect of internet on our society.
\end{abstract}

\section{KEYWORDS}

Internet, Society, Causal loop, Fuzzy

\section{INTRODUCTION}

The continuous changing technology has brought effect on social and economic consequences on different aspects of our daily life. Two aspects of this technology emerged are "Positive and Negative impact" on the users. Our approach is to avoid wrong choices otherwise our technology will destroy us. The internet has influenced different aspects of society. It is important for us to understand the consequences of internet on the people life and habits. A. Venkatesh [1] surveyed in his paper that all technologies create an impact of some sort like attributes and behavior toward entertainment and the interaction between families. Cole [2] assessed the need of the internet as a mainstream medium that may soon be as pervasive as television, although the speed of its diffusion seems much faster. Kraut et. al [3] conducted a longitudinal study of the effects of the internet on social involvement and psychological effect of the internet, decreased community within the family, decreased local social network, lethargy and depressions. In a report of SIQSS, N. Nie [4] has sustained the negative consequences of the internet. Kraut and Katz et. al. [3] has shown that the internet has a negative effect on society.

The long internet usage was analyzed by Young [5]. It was coined Internet addiction disorder. Persons with IAD can exhibit symptoms, suffer drawbacks and face consequences that are similar to individual addicted to alcohol, gambling, narcotics shopping and compulsive behavior. These persons find the virtual environment to be more attractive than everyday reality. Their daily lives are dominated by their need to be online. This is affecting millions of American, Europeans and even in Asian countries. 


\section{Statement Of Problem}

As the use of internet is growing rapidly each year, the negative internet effect has become a problem among the users. Internet users may come from all walks of life and as a result, they are suffering in the main aspects of everyday life in situations such as education, job, family and social relationship. In this work the relationship is formed between the different parameters and analyzes the effect of internet on considering professionals, academicians and students. The parameters considered are made more understandable by designing a questionnaire and taking interviews to analyze the effect of the internet on society using intelligent system.

\section{METHODOLOGY}

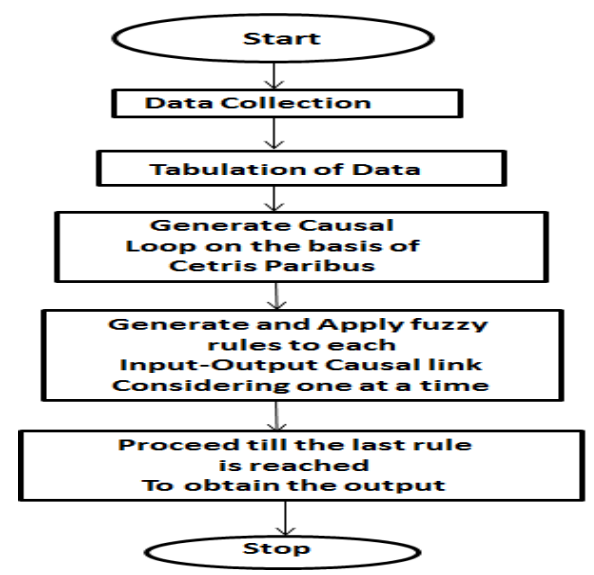

Fig.1. Flow Chart for the Intelligent Analysis using Causal loop and Fuzzy logic

*Input for each fuzzy rule based on Causal link is from the Survey result represented as COG\%

\subsection{Data source}

The sample is taken from the population having different demographics like teens and adults of different professions like academicians, professionals and students. 50\% ratio of male and female are taken. In this paper data is not analyzed separately, but the relationship between parameters is taken. Degree of agree is calculated from the center of gravity method.

\subsection{Causal Loop Diagram.}

On the basis of the parameters an internet system is formed with the help of a causal loop diagram. Causal loop diagramming (CLD) encourages the modeler to conceptualize a real world system in terms of feedback loops [6]. Causal loop plays two important roles in system dynamics studies. First, during model development, they serve as preliminary sketches of causal hypotheses. Second, the causal loop diagram can simplify the illustration of a model [7].

CLD is a foundational tool used in system dynamics [8]. A method of analysis used to develop and understand the complex system. It provides the systematic feedback in the processes by the variable $\mathrm{x}$ affects variable $\mathbf{y}$ and, in turn y affects $\mathbf{z}$ variable through a chain of causes \& effects. The behavior of the entire system is discovered with CLD [9] [10]. CLD can focus on the entire system [16]. There are linguistic variables in our system and hence fuzzy logic is used. 


\subsection{Fuzzy Set Theoretic Approach.}

Natural language abounds with vague and imprecise concepts, such as "Anjali is tall", "he has acute pain". Such statements are difficult to translate into more precise language without losing some of their semantic values [11] [12].

Fuzzy logic is a superset of conventional (Boolean) logic that has been extended to handle the concept of partial truth values between completely true and completely false [13] [14]. It was introduced by Dr. Lofti Zadeh of University of California, Berkley in the year 1965. Fuzzy system combines fuzzy sets with fuzzy rules to produce overall complex nonlinear behavior [17]. Fuzzy formulation can help to achieve tractability, robustness and lower solution cost [15].

\section{SURVEY AND EXPERIMENT RESUlT}

According to data survey an intelligent model is formed to analyze the effect of the internet on society. The complete research is done in four phases represented as below:

1. Data Collection: Primary Data is collected using the survey method of preparing questionnaire. The samples are taken from a population by using random sampling considering students, academicians and professionals with both male and female in all entities.

2. Data Tabulation: The data collected is tabulated in terms of frequency response from the questionnaire, based on Likert scale and then the centre of gravity for the degree of agree is calculated for each parameter.

3. Data Analysis: The data are analyzed using causal loop and fuzzy system models to determine the effect of the internet in society.

4. Data representation: The output results are represented by graphs and tables.

\subsection{Model development Phase}

Step1 (Data Collection) - The questionnaire is prepared using the given parameters and survey is done by asking the respondent in terms of strongly disagree, disagree, neutral, agree and strongly agree for each parameter. The response was taken for both male and female from each group of students, academicians, and professionals.

The following parameters were chosen in the questionnaire

1. Long Internet Usage (LIU)

2. Internet Usage for Job purpose (IJP)

3. Easy Internet Access (EIA)

4. Internet Entertainment Engagement (IEE)

5. Internet Usage Cost (IUC)

6. Medical problems (MP)

7. Ethical Problems (EP)

8. Social restrictions (SR)

9. Lethargy uses the Internet (LUI)

10. Psychological Problem (PP)

11. Spoilage of teenagers (SOT)

12. Crime Uplift (CU)

13. E-business (EB)

Step 2 (Data Tabulation) - The second step in the model development phase is the identification of variables and tabulation of response from the survey. The variance identified are tabulated in terms of frequency and center of gravity for the degree of agree is calculated between $0-100 \%$ scale as shown in Table 1. 
Table 1. Tabulated results prepared from surveys using Likert Scale

\begin{tabular}{|l|l|l|l|l|l|l|}
\hline Parameters & SD & $\mathbf{D}$ & $\mathbf{N}$ & $\mathbf{A}$ & SA & $\begin{array}{l}\text { COG } \\
(\%)\end{array}$ \\
\hline LIU & 3 & 8 & 6 & 24 & 19 & 76.2 \\
\hline IJP & 0 & 4 & 4 & 23 & 29 & 85.6 \\
\hline EIA & 0 & 1 & 4 & 25 & 30 & 88.0 \\
\hline IEE & 2 & 5 & 12 & 27 & 14 & 75.2 \\
\hline IUC & 16 & 27 & 8 & 8 & 1 & 43.6 \\
\hline MP & 0 & 3 & 11 & 25 & 21 & 81.2 \\
\hline EP & 4 & 7 & 14 & 27 & 7 & 68.8 \\
\hline SR & 4 & 7 & 15 & 25 & 9 & 69.2 \\
\hline LUI & 0 & 3 & 11 & 37 & 9 & 77.2 \\
\hline PP & 3 & 7 & 18 & 22 & 10 & 69.6 \\
\hline SOT & 1 & 4 & 8 & 21 & 26 & 82.2 \\
\hline CU & 2 & 1 & 5 & 30 & 18 & 81.6 \\
\hline EB & 3 & 0 & 4 & 23 & 30 & 85.6 \\
\hline
\end{tabular}

$\mathrm{SD}=$ Strongly Disagree, $\mathrm{D}=$ Disagree, $\mathrm{N}=$ Neutral, $\mathrm{A}=$ Agree, $\mathrm{SA}=$ Strongly Agree, $\mathrm{COG}=$ Centre of Gravity.

Step 3 (Data Analysis) - For Data analysis, intelligent system is developed having two parts, the first part is the causal loop for formation of relationship between parameters, and the second part is fuzzy logic for determining the result of the effect of the internet in the society.

Causal links have been developed between a pair of variables under Ceteris paribus condition (keeping other variables constant) as in the system dynamics methodology. From these causal links, a causal loop diagram is drawn as shown in the fig. 4.1.

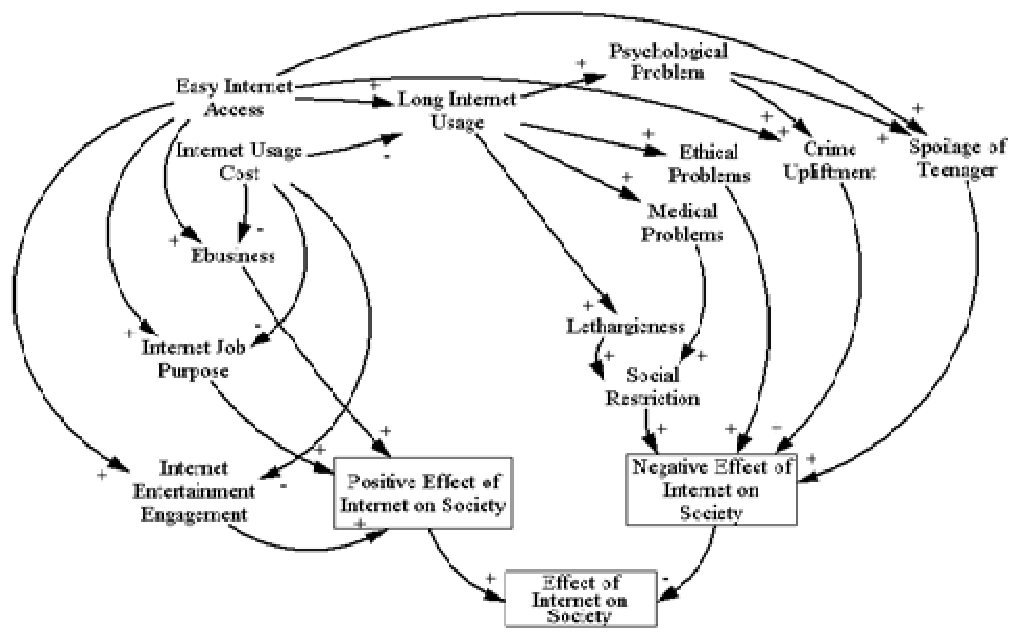

Fig.2. Causal loop diagram for Internet System

Fuzzy knowledge base is developed from causal links. The fuzzy rules are formed for a causeeffect relationship between independent parameters and dependent parameters to determine the output in terms of dependencies.

Rule 1: If EIA is high, then LIU high ELSE if EIA is medium then LIU is medium ELSE if EIA is low then LIU is LOW. 
Rule 2: If IUC is low, then LIU is high ELSE if IUC is medium then LIU is medium ELSE if IUC is high then LIU is LOW.

Rule 3: EIA is low and IUC is low, then IJP and IEE and EB are medium ELSE if EIA is low and IUC is medium then IJP and IEE and EB are medium low. ELSE if EIA is low and IUC is high then IJP and IEE and EB are low ELSE if EIA is medium and IUC is low then IJP and IEE and EB are medium high ELSE if EIA is medium and IUC is medium then IJP and IEE and EB are medium ELSE if EIA is medium and IUC is high then IJP and IEE and EB are medium low ELSE if EIA is high and IUC is low then IJP and IEE and EB are high ELSE if EIA is high and IUC is medium then IJP and IEE and EB are medium high ELSE if EIA is high and IUC is high then IJP and IEE and EB are medium.

Rule 4: If LIU is high, then PP and EP and MP and LUI are high ELSE if LIU is medium then PP and EP and MP and LUI are medium ELSE if LIU is low then PP and EP and MP and LUI are low.

Rule 5: If EIA is low and PP is low then CU and SOT are low ELSE if EIA is low and PP is medium then CU and SOT are medium low ELSE if EIA is low and PP is high then CU and SOT is medium ELSE if EIA is medium and PP is low, then CU and SOT are medium low ELSE if EIA is medium and PP is medium then CU and SOT are medium ELSE if EIA is medium and PP is high, then CU and SOT are medium high ELSE if EIA is high and PP is low, then CU and SOT are medium ELSE if EIA is high and PP is medium then CU and SOT are medium high ELSE if EIA is high and PP is high then CU and SOT are high.

Rule 6: If LUI and MP is high, then SR is high ELSE If LUI and MP are medium, then SR is medium ELSE If LUI and MP is low then SR is low.

Rule 7: If EP and CU and SOT and SR are low, then NEIS is low ELSE If EP and CU and SOT and SR are the medium, then NEIS is medium ELSE If EP and CU and SOT and SR are high then NEIS is high.

Rule 8: If EB and IJP and IEE are high, then PEIS is high ELSE If EB and IJP and IEE are the medium, then PEIS is medium ELSE If EB and IJP and IEE are low then PEIS is low.

The results for fuzzy relationship considering each rule are implemented and shown in the figure:

\section{Step 4 (Data Representation)}

Fuzzy rule 1 is implemented for the total range representing one to one positive cause effect relationship. The input variable is taken as Easy Internet Access and the output variable is taken Long internet usage. The Causal link is represented in Fig.3 and fuzzy rule output in Fig.4.

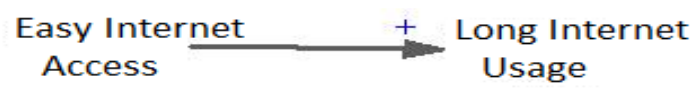

Fig.3. Cause effect relationship between EIA and LIU 
International Journal on Cybernetics \& Informatics (IJCI) Vol. 3, No. 3, June 2014

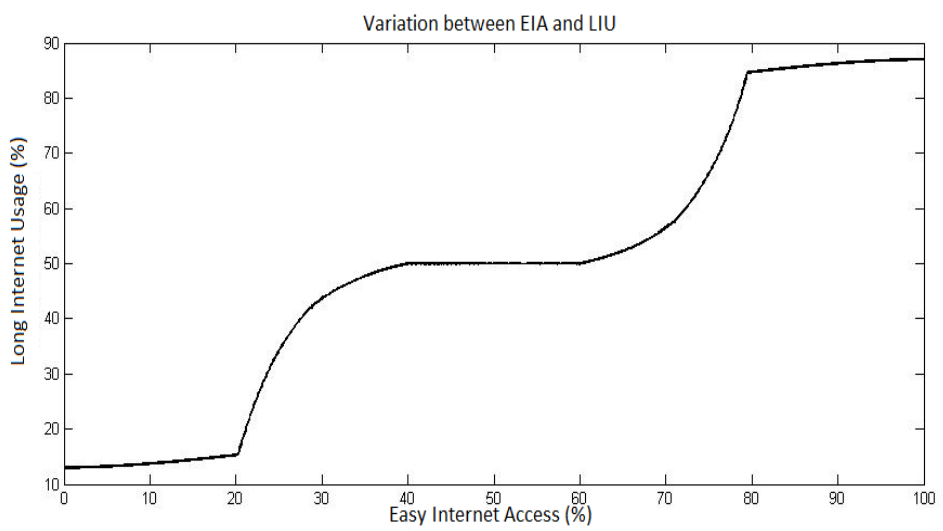

Fig.4. Fuzzy output between Easy Internet Access (\%) and Long Internet Usage (\%)

Fuzzy rule 2 is implemented for the total range representing one to one negative cause effect relationship. The input variable is taken as Internet Usage Cost and output variable is taken as Long Internet Usage. The Causal link is represented in Fig.5 and fuzzy rule output in Fig.6

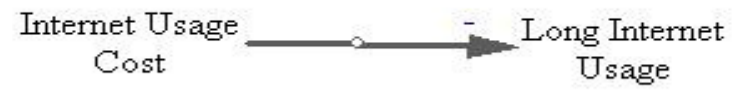

Fig.5. Cause effect relationship between IUC and LIU

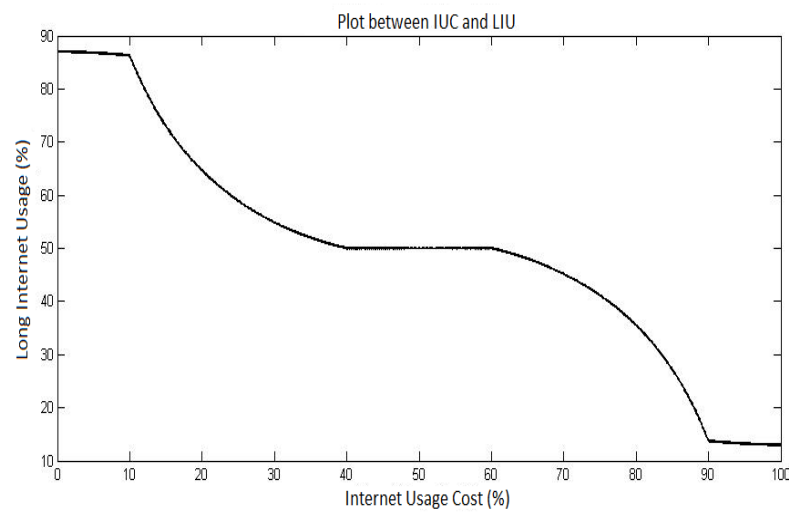

Fig.6. Fuzzy output between Internet Usage Cost (\%) and Long Internet Usage (\%)

Fuzzy rule 3 is implemented taking an Easy Internet Access and Internet Usage Cost as input and Internet job purpose as output. The Causal link is represented in Fig.7 and fuzzy rule output in Fig.8.

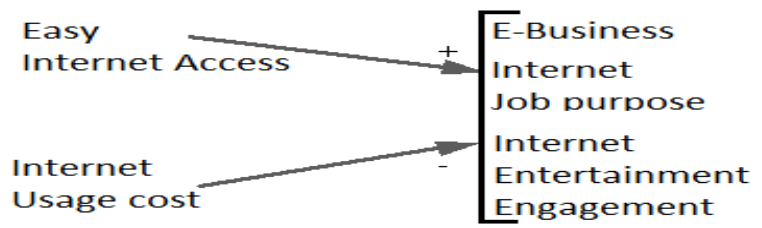

Fig.7. Cause effect relationship between EIA, IUC and IJP 


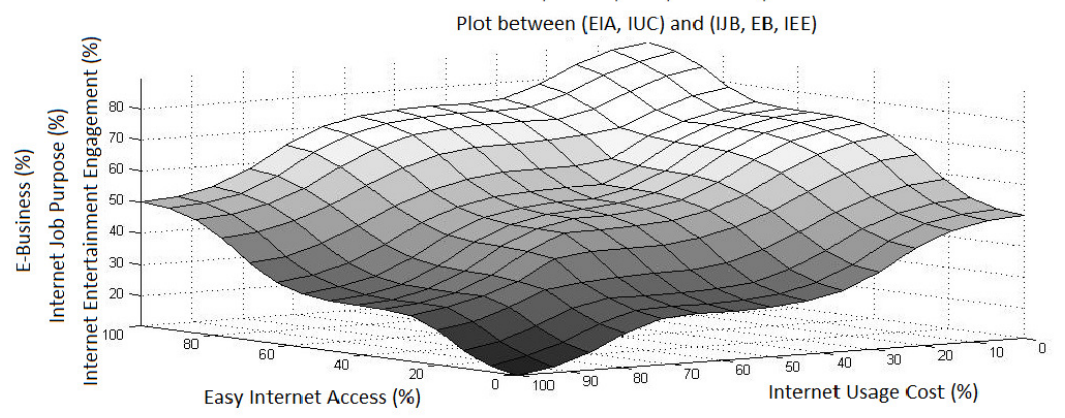

Fig.8.Fuzzy rule output between Internet Usage Cost (\%), Easy Internet Access (\%) and Internet Job Purpose $(\%)$

Fuzzy rule 4 is implemented taking Long internet usage as input while Psychological problem, Ethical problem, Medical Problem and Lethargy problem as output. The Causal link is represented in Fig.9 and fuzzy rule output in Fig.10.

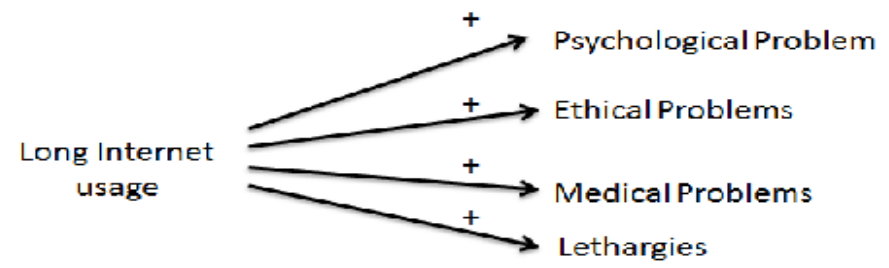

Fig.9. Cause effect relationship between LIU with PP, EP, MP and LUI

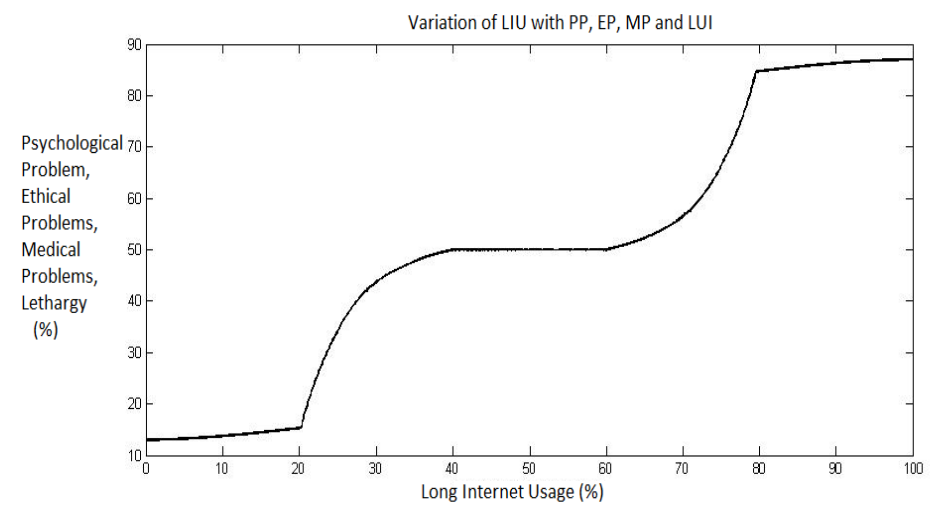

Fig.10. Fuzzy output between Long internet Usage (\%) with Psychological Problem (\%), Ethical Problem

(\%), Medical Problem (\%) and Lethargy (\%)

Fuzzy rule 5 is implemented taking Easy internet Access and Psychological Problem as input and Spoilage of teenagers as output. The Causal link is represented in Fig. 11 and fuzzy rule output in Fig.12.

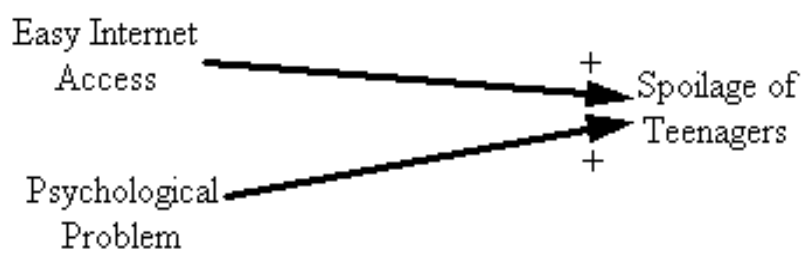

Fig.11. Cause effect relationship between EIA, PP and SOT 


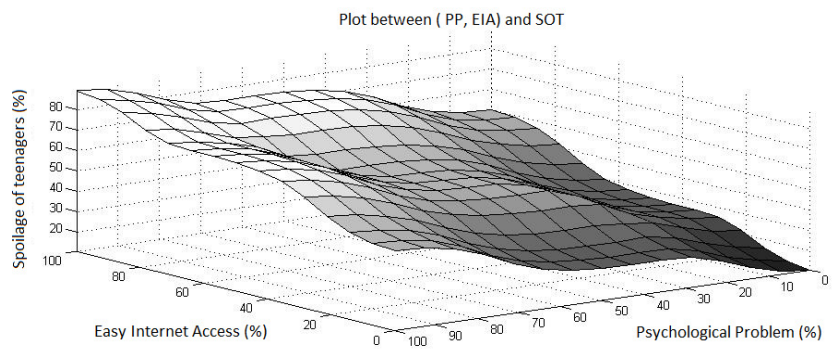

Fig.12. Plot between Psychological Problem (\%), Easy Internet Access (\%) and Spoilage of teenagers (\%)

Fuzzy rule 6 is implemented taking Easy internet Access and Psychological Problem as input and Spoilage of teenagers as output. The Causal link is represented in Fig.13 and fuzzy rule output in Fig.14.

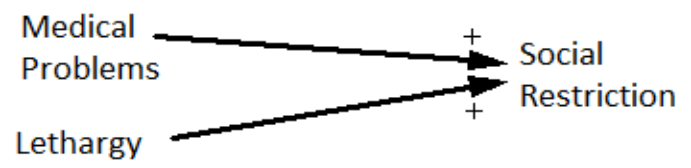

Fig.13. Cause effect relationship between MP, LUI and SR

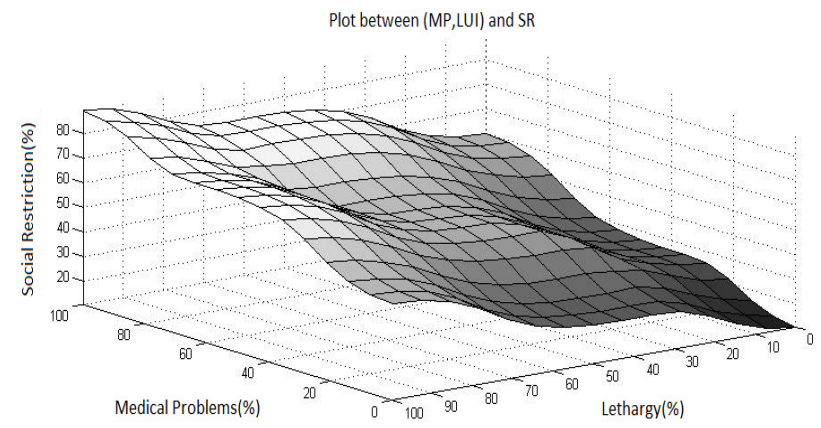

Fig.14. Plot between Medical Problems (\%), Lethargy (\%) and Social Restriction (\%)

Fuzzy rule 7 and Fuzzy rule 8 are implemented using the cause effect relationship to determine the negative and positive effect of the internet on the society by moving in the causal relationship.

Fuzzy rule 7: One to one cause effect relationship is shown in Fig.15 and fuzzy rule output in Fig.19.

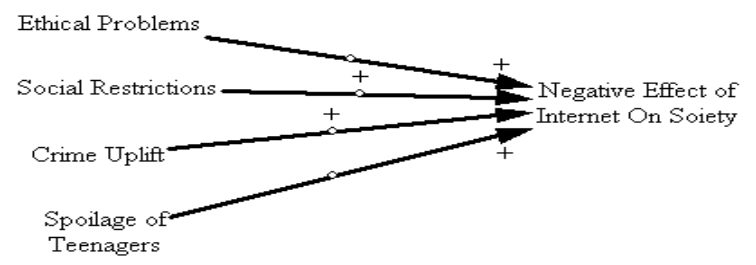

Fig.15. Cause effect relationship between EP, SR, CU, SOT and NEIS 
Ethical problems, social restriction, crime uplift and spoilage of teenagers are taken as input. The negative effect of internet on society is taking as output. Fuzzy model is created with input membership functions as shown in Fig.16.

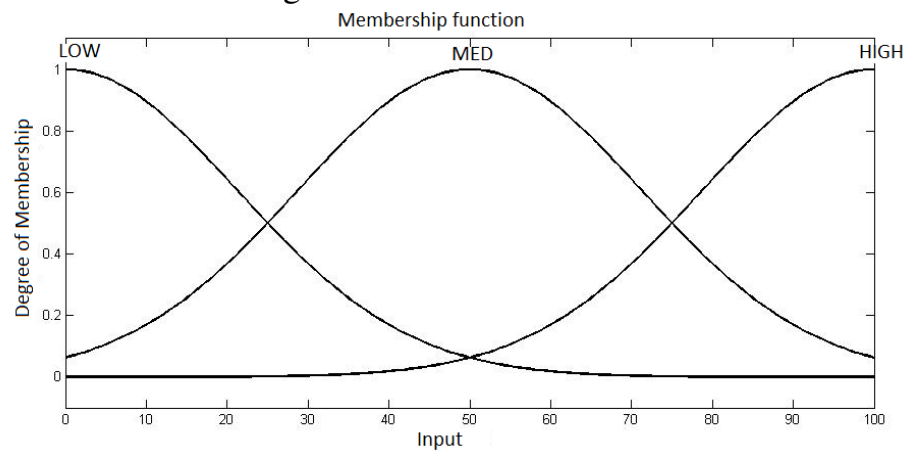

Fig.16. Input membership function for fuzzy rule 7 and 8

The output membership functions are created for the negative effect of internet on society Fig 17.

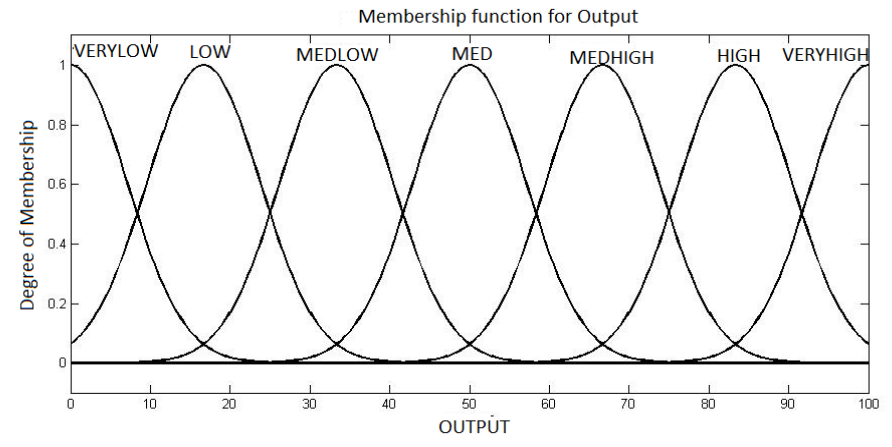

Fig.17. Output membership function for fuzzy rule 7 and 8

The effect of Ethical Problems and Spoilage of teenagers in society, creating negative effect is shown in Fig 18.

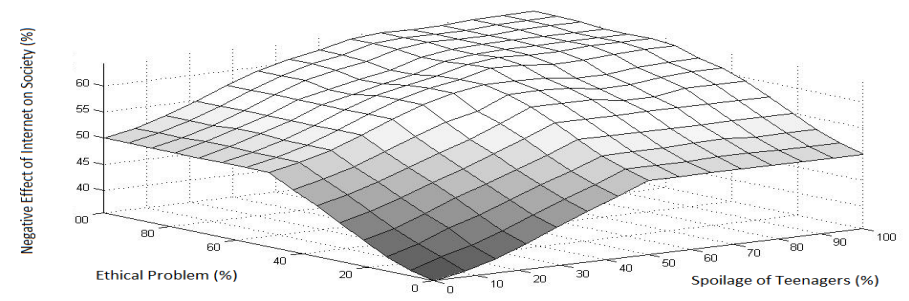

Fig.18. Plot between Ethical Problems (\%), Spoilage of Teenagers (\%) and Negative effect of Internet on Society $(\%)$

Considering all the input parameters for complete range the variation of Negative Effect 
International Journal on Cybernetics \& Informatics (IJCI) Vol. 3, No. 3, June 2014

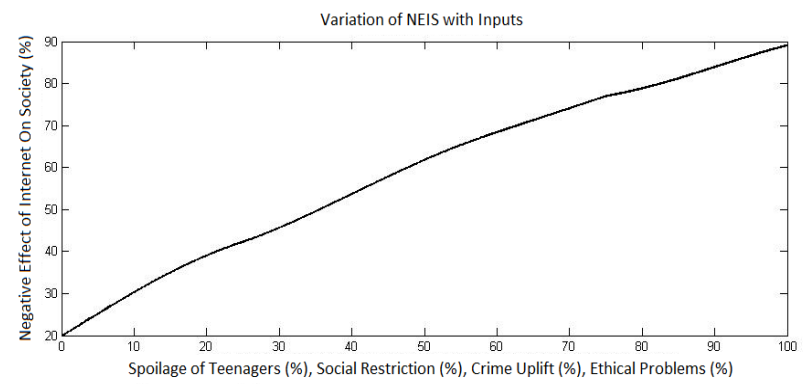

Fig.19. Plot for Negative effect of Internet on Society with variation of input parameters

Fuzzy rule 8 one to one cause effect relationship is represented by the Causal link is represented in Fig.20 and fuzzy rule output in Fig.22.

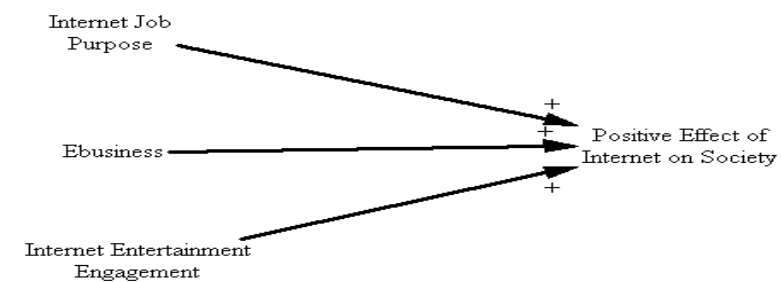

Fig.20. Cause effect relationship between IJP, EB, IEE and PEIS

Internet Job Purpose, Internet Entertainment Engagement, Ebusiness is taken as input and Positive Effect of Internet on Society is taken as the output. The membership function is defined as for fuzzy rule 8 shown in Fig.21.

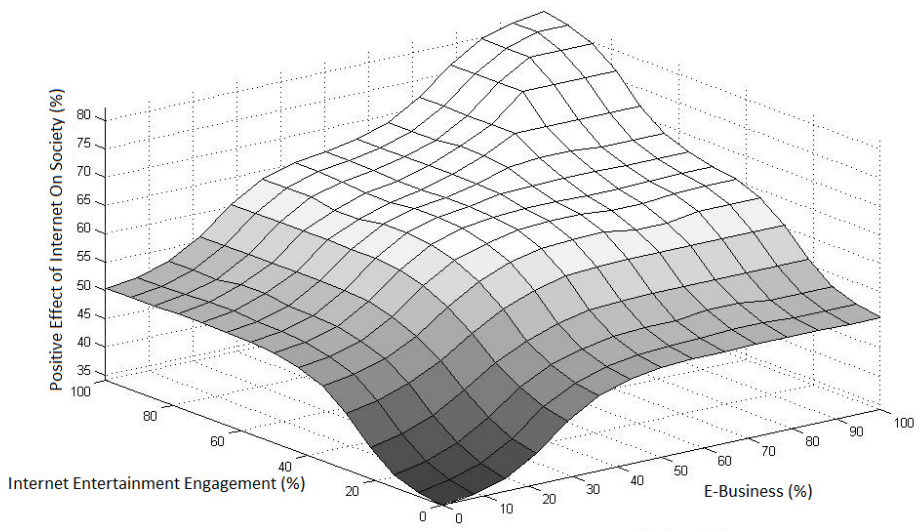

Fig.21. Plot between Internet entertainment engagements (\%), E-business (\%) and Positive Effect of Internet on Society $(\%)$ 


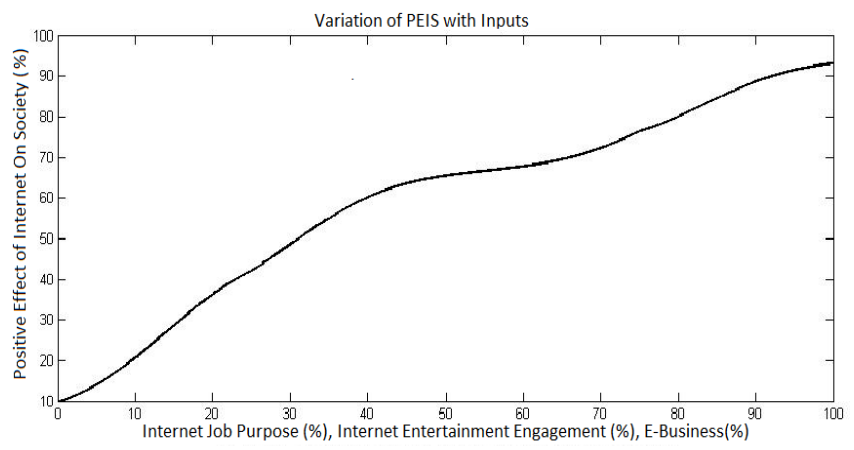

Fig.22. Plot for Positive effect on Society with variation of input parameters

According to fuzzy rules the positive effect and negative effect of internet usage is determined for academicians, professionals, students on the basis of gender by doing inference. Table 2 represents the percentage positive effect and negative effect.

Table 2. Positive and Negative Effect of internet usage in society

\begin{tabular}{|l|l|l|l|}
\hline \multicolumn{1}{|c|}{ Category } & Gender & $\begin{array}{c}\text { PEIS } \\
(\boldsymbol{\%})\end{array}$ & $\begin{array}{c}\text { NEIS } \\
(\%)\end{array}$ \\
\hline Professional & $\mathrm{M}+\mathrm{F}$ & 80.4 & 76 \\
\hline Academicians & $\mathrm{M}+\mathrm{F}$ & 80.7 & 79.4 \\
\hline Students & $\mathrm{M}+\mathrm{F}$ & 80.6 & 77.9 \\
\hline $\begin{array}{l}\text { Professionals+ } \\
\text { Academicians+ Students }\end{array}$ & $\mathrm{M}$ & 80.7 & 79.2 \\
\hline $\begin{array}{l}\text { Professionals+ } \\
\text { Academicians+ Students }\end{array}$ & $\mathrm{F}$ & 79.1 & 77 \\
\hline $\begin{array}{l}\text { Professionals+ } \\
\text { Academicians+ Students }\end{array}$ & $\mathrm{M}+\mathrm{F}$ & 80.7 & 77.9 \\
\hline
\end{tabular}

PEIS = Positive effect of internet on society, NEIS= Negative effect of internet on society, $\mathrm{M}=$ male, $\mathrm{F}=$ female.

According to survey parameters, the output for positive effect and negative effect of internet is shown in table II. Although positive effects of internet are high, but simultaneously the negative effect is also high. This is a major problem for the society. The internet negative effect is arising due to use of internet for gambling in virtual casinos, playing games, chatting with strangers, day trading, watching violence and pornography, searching for information not relevant to work. The effect is that the people start getting restless, irritable, guilty, excess fatigue, anxious and also suffer from depression. The professionals loose the interest in the work and hence it drops the productivity. Although the merits of the Internet make it an ideal research tool, but students surf irrelevant websites, engage in chat room gossip, converse with Internet pen pals, and play interactive games at the cost of productive activity. This cause student as well as teachers to become lethargic, compels them to say lie to others, lose concentration on studies, decline in results. To avoid such negative impact of internet on society, people should start social interaction with people, spend some time outside in the early morning and evening doing exercises and meeting friends. 


\section{Conclusions}

In this paper, the results of the survey and fuzzy experiments on the negative and positive effect of the internet on society are presented. The results suggest that the negative effect of internet like medical problem, social restriction, psychological problems, spoilage of teenagers is occurring which may result in a chronic disease and destroy our society. Necessary steps should be taken to remove the problems, so that the internet can be used for the welfare of society.

\section{REFERENCES}

[1]A.Venkatesh, (1985) “A conceptualization of household/technology Interaction", Advances in consumer research, Vol.12, pp189-194.

[2]J.I Cole "the Impact of internet on our Social, Political and Economic life". UCCLA centre of communicating policy.

[3]R, kraut, M.Patterson, V.Lundmark, (1998) “A social Technology that reduce social involvement and psychological wellbeing”, American Psychologist 53 (a).

[4]N. Nie, (2000) "Study of Social consequences of the internet", Stanford Institute of quantitative study of society (SIQSS).

[5]J.katz, P.Aspeden, (1997) "Motivation for the barriers to internet usage", Internet research Electronic Networking application and policy, Vol. 7, pp170.

[6]Richardson, G. P., (1986) "Problems with causal-loop diagrams", System Dynamics Review, 2(2), pp158-170.

[7]Kim, D. H., (1992) “Guidelines for drawing causal loop diagrams”, The Systems Thinker, 3(1), pp5-6.

[8]Wolstenholme, E. F., (1999) "Qualitative vs. quantitative modelling: the evolving balance", Journal of the Operational Research Society, pp422-428.

[9]Anderson, V., \& Johnson, L. (1997). Systems thinking basics. Pegasus Communications.

[10]Morecroft, J. D. (1982) "A critical review of diagramming tools for conceptualizing feedback system models", Dynamica, 8(1), pp20-29.

[11]Sugeno, M., \& Yasukawa, T., (1993) “A fuzzy-logic-based approach to qualitative modelling”, IEEE Transactions on fuzzy systems, 1(1), pp7-31.

[12]Yager, R. R., \& Filev, D. P. (1994). Essentials of fuzzy modelling and control. New York.

[13]Mamdani, E. H. (1977) "Application of fuzzy logic to approximate reasoning using linguistic synthesis”, Computers, IEEE Transactions on, 100(12), pp1182-1191.

[14]Pavelka, J. (1979) “On Fuzzy Logic I Many-valued rules of inference”, Mathematical Logic Quarterly, 25(3-6), pp45-52.

[15]Ross, T. J. (2009). Fuzzy logic with engineering applications. John Wiley \& Sons.

[16]Chaturvedi, D. K., (2005) "Dynamic model of HIV/AIDS Population of Agra Region", Int.J.Environ. Res. Public Health, 2(3), pp420-429.

[17]D.K. Chaturvedi, (2008) Soft computing techniques and its applications in Electrical Engineering, Studies in Computational Intelligence (SCI) 103.

\section{Authors}

Rashmi Chahar is working in the field of intelligent systems. Her focus is to develop expert systems for the welfare of the society. She has published papers in journals and conferences and conducted workshops for improvement of research.

Ashish Chandiok is working in the field of Cognitive systems. His focus is to develop cognitive systems for industrial application. He has published several papers in journals and given expert lectures in the field of soft computing, Research Methodology and intelligent systems.

Prof. D. K. Chaturvedi is working in the field of Soft Computing, Cognitive systems and Conscious System. He has published 90 journals, authored two books published in Springer and CRC. He has guided several PhD Students in the field of soft computing and intelligent system.
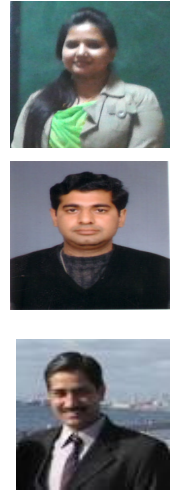